\title{
Readers' experiences of fiction and nonfiction influencing critical thinking
}

Helena Hollis

UCL Department of Information Studies

ORCID: https://orcid.org/0000-0003-1950-0657

Please cite as:

Hollis, H. (in press) Readers' experiences of fiction and nonfiction influencing critical thinking. Journal of Librarianship \& Information Science. 


\begin{abstract}
This study investigated readers' experiences of critical thinking and reading, comparing fiction and nonfiction. As previous research has shown links between fiction reading and increased social and cognitive capacities (Mumper \& Gerrig, 2017), and such capacities are argued to be necessary for critical thinking (Kuhn, 2019), this study sought to explore a potentially unique relationship between reading fiction and critical thinking, as distinct from nonfiction. In depth interviews were conducted with participants who self-identified as readers $(N=12)$. Each reader was interviewed twice, first in a general discussion of their reading and critical thinking experiences, and secondly with reference to a text they selected to read. An open, iterative coding process yielded 10 codes from the data, forming 5 categories. These show links between reading experiences and critical thinking, the integration of critical thought into the reading experience through transportation into the text, and also differentiate fiction from nonfiction influences. Nonfiction was valued for its directness, assessable authorship, and questioning. Fiction was found to uniquely drive critical evaluations through the subtle and circuitous way it presented ideas, its complication of veracity, as well as giving rich and deep understandings of the real world. These findings suggest fiction reading experiences are connected with critical thinking in ways distinct to nonfiction, and as such could be an avenue for promoting critical thinking across society through public library provision.
\end{abstract}




\section{Introduction}

By seeking commonalities and differences between readers' fiction and nonfiction experiences, in relation to thinking critically, this study aimed to identify ways that fiction may play a unique role in critical thinking. However, as Friend (2008) points out, a hard definition that permits a definitive sorting into distinct fiction/nonfiction categories is unobtainable as there will always be fringe cases and counterexamples, and differences in the ways people think about what constitutes fiction and nonfiction. For librarians, cataloguing fiction has thus been argued to post unique issues (Ward \& Saarti, 2018), though this approached in terms of cataloguing different genres of fiction rather than fiction versus nonfiction. For the purposes of this study, philosophical approaches for differentiating fiction and nonfiction were drawn from; other approaches fall beyond the scope of this paper, but work from sociology and cultural studies approaches could also be utilised for a more robust understanding of these terms.

In order to establish a means of differentiating fiction and nonfiction, while acknowledging overlaps and liminality between them, this study adopts Currie's "intentional approach" which places the classification of fiction and nonfiction in the intentions of the author, and the reader's recognition of those intentions; by Currie's definition, fiction is that which invites make-belief. By contrast, nonfiction invites belief (Root, 2004). Readers recognise the authors' intentions, and respond to the text accordingly (make-believing in the case of fiction, and believing or disbelieving in the case of nonfiction), which is how fiction and nonfiction are differentiated for Currie. As readers make judgements on authors' intent and are adept at distinguishing between texts intended to be believed or make-believed (Sutrop, 2002), this approach offers a naturalistic distinction between fiction and nonfiction. 
Furthermore, the intentional approach to defining fiction chimes with calls for library classification to acknowledge different readers understandings (Ward \& Saarti, 2018). Nonfiction has been strongly focused on in previous information literacy (IL) research, which has emphasised "informational reading" to obtain knowledge (Hampson Lundh et al., 2018). This has focused on conditions under which we should believe or disbelieve information, typically by judging source quality (e.g. D’Angelo, 2001). By contrast, Hampson Lundh and colleagues point out that little focus has been given to "experiential reading", which would include make-belief of fiction, and focus on content over source. Therefore this study includes nonfiction reading, but is primarily focused on fiction in contrast to this as an under-researched area in IL, seeking to identify ways that fiction may offer some unique pathways to critical thinking (CT).

Fiction is typically valued for its literary merit, and framed in educational terms as offering rich material for interpretation and analysis, as part of wider arguments for the importance of the arts and humanities as stimulating critical thought (Dumitru, 2019). More widely than just the literary, reading fiction has been argued to be beneficial for broadening cultural perspectives through exposing us to the lives of characters outside of our own range of experiences (Hakemulder, 2001). As such, the value of fiction is typically sought in its style, or its contents. However, research in psychology has found links between fiction reading and performing mental simulations that build our ability to engage with other's perspectives and to imagine counterfactual possibilities (Oatley, 2011). As engaging with different perspectives (Kuhn, 2019), and imagining alternative possibilities (Byrne, 2016), are essential abilities for $\mathrm{CT}$, the argument that forms the rationale for this study is that these benefits of fiction reading may feed into capacities for critical thought. This would imply that 
it is the experience of simulating fictional narratives while reading, regardless of the literary merit or specific contents of the text, that can provide benefits.

CT is argued to be necessary for effective democratic engagement (Facione, 1990; Frímannsson, 2016; Gainer, 2012; Siegel, 1997).The argument for the need for each individual to think critically about each piece of information they read so as to be able to participate in social and democratic life has been brought to the fore in current concerns surrounding "fake news" (Batchelor, 2017; Machete \& Turpin, 2020). Subsequently, ways of promoting CT in society ought to be valued. The case for fiction reading as a means for boosting $\mathrm{CT}$ is a case for the value of providing access to fiction, therefore for the need for public libraries. Given the current context of ongoing funding cuts to public library services (Flood, 2020), evidence for their benefits is crucial.

As this study was focused on the experience of reading fiction, being transported into the world of the text, and the specific ways of thinking critically that could arise, a qualitative research approach was taken. In order to explore readers' experiences of reading and thinking critically, in depth interviews were conducted. Readers of fiction and nonfiction were recruited, and both types of reading material included in the interviews, in order to enable a comparison so as to find similarities and unpick any unique experiences attributed to fiction. This study revealed both commonalities between fiction and nonfiction reading in their relationship with $\mathrm{CT}$, and unique connections between each type of reading and approaches to critical thought. The study was conducted as part of a wider PhD research project on fiction reading and critical thinking.

The research questions guiding this study were: 
a. In what ways do readers experience an influence of what they read on how they think critically?

b. In what ways do readers' experiences pertaining to question a. differ between fiction and nonfiction reading? Are there any unique associations for fiction?

c. How do readers' experiences of transportation (being immersed into the text) while reading relate to the ways in which they think critically about a text?

\section{Literature Review}

\section{Information Literacy, Critical Thinking, and Fiction}

The literature was reviewed with an iterative hermeneutic method (Boell \& Cecez-

Kecmanovic, 2010). As research on IL, CT, and the effects of reading fiction is highly interdisciplinary, including fields such as philosophy, psychology, and literary studies as well as library and information science (LIS), a hermeneutic approach permitted openness in the literature selection process. This review first presents an overview of IL and CT, and ways fiction may be connected to these. Next, an applied and contextualised approach within a public library context is addressed.

Most recent definitions and conceptions of IL tend to focus on critical evaluation, deemphasising more basic source evaluation skills, which has been captured in the most recent CILIP definition of IL:

\footnotetext{
"Information literacy is the ability to think critically and make balanced judgements about any information we find and use. It empowers us as citizens to reach and express informed views and to engage fully with society" (CILIP, 2018)
} 
This takes the focus away from searching for information (CILIP, 2017), and towards thinking critically about the content of all forms of information we encounter. Furthermore, CT and making balanced judgements is inherent in all other facets of IL, e.g. identifying what information is needed requires critical thought also. Therefore, critical thought underpins the concept of IL as a whole, as is arguably the most integral component of it.

$\mathrm{CT}$ is a distinct concept that has rich literature base of its own. In a previous analysis I have argued that conceptions of IL and of CT strongly overlap, such that while they may emphasise different basic skills they aim for the same broader competencies and stronger sense overarching goals (XX, 2019). CT was therefore taken to be the primary aspect of IL, and focused on for this study. A review of the CT literature with all of its definitions falls beyond the scope of this paper. For the purposes of this study, CT is taken to encompass the evaluation of information, including: reasoning about possible biases and framings (Ennis, 2016); being open to different points of view (Paul, 1981) and empathetically engaging with others (Thayer-Bacon, 2000); imaginatively simulating different possibilities (Byrne, 2016); broader creative and imaginative capacity to engage with and create information (Bailin, 1987). To give an example, if we are to think critically about an argument in favour of, say, introducing universal basic income (UBI), we need to consider the position of the person presenting it and how their background and affiliations may be informing and motivating their case; we need to be open to arguments that contradict our own position; we need to be able to empathetically understand the lives that could be impacted, as well as reading the emotionality of the argument; we must imagine what the world would look like if UBI was in effect, what could be different and how in a variety of alternatives; we also need to be imaginative in our responses to this argument, perhaps considering novel ideas to take the conversation further. 
All of these facets of CT, which also feature in understandings of IL, have been associated with fiction reading in previous research. People who read more fiction have been found to have increased levels of empathy and greater ability to model the minds of others (Mar et al., 2006); furthermore, the positive correlation between fiction and empathy is well replicated (Fong et al., 2013; Mar et al., 2009; Mumper \& Gerrig, 2017; Stansfield \& Bunce, 2014; Tamir et al., 2016). When we engage with characters in a novel, we are able to place ourselves into their position, and to feel with them as they traverse various emotions through the vicissitudes of the fictional narrative. This suggests that fiction readers may be better able to empathetically engage with the viewpoints of others, which is necessary for CT (Paul, 1987; Thayer-Bacon, 2000). Furthermore, fiction reading is also connected with greater capacity to imaginatively simulate different situations and scenarios (Oatley, 2011), and being open to different possibilities in counterfactual reasoning (Black et al., 2017). Fictional worlds can be highly diverse, presenting situations and events vastly different from our everyday lives, with narratives tracking the trajectories arising from various decisions, engaging us with alternate realities. Again, engaging with counterfactual alternatives is necessary for critical thought (Byrne, 2016). To link this back to our UBI example, it may that a reader who has had plenty of practice stepping into the shoes of fictional characters will be better able to put themselves into the position of the author of the argument and judge what could be motivating it, as well as being better able to imagine the lived experiences of those UBI could impact. This fiction reader might also have had more exposure and practice imagining fictional worlds completely alien from our own, making them more open to very different ways the world could be such as with UBI introduced, and also making the world in which UBI is a reality much easier to simulate and picture in different ways. 
Fiction reading is believed to confer these benefits by providing simulative practice for reallife interactions, effectively training these capabilities (Zunshine, 2006). Narrative transportation, which is the experience of being immersed into the story world such that it is vividly felt and perceived (Gerrig, 1993), is argued to enable fiction to confer these benefits. The way that fiction can transport us into other worlds such that we vividly experience events has been compared to a flight simulator (Mar et al., 2008); we can engage in all kinds of activities and interactions in our minds as we taken along the fictional journey, from the safety of our armchairs. The transportation into the narrative has also been found to mediate the relationship between reading fiction and empathy (Johnson, 2012), suggesting it is the highly engaged and immersed state that drives the fictional benefits. Therefore, prior research suggests that it is the immersive, transporting experience of reading fiction which can uniquely train social and imaginative abilities.

These findings suggest an avenue through which fiction readers may have increased CT capacities. By reading fiction, readers may practice imaginatively stepping into the position of others and imagining the world through their eyes. They may thus get better at understanding different perspectives, and become more open to different viewpoints. They may also train wider imaginative capacities to think through different scenarios, modelling the outcomes of different possibilities. As such, reading fiction may play a unique role in developing capacities for critical thought.

\section{Fiction, IL, and CT in Public Libraries}

Public libraries are places of informal lifelong learning for all (McNicol \& Dalton, 2003), and have a key role to play in democratic societies by engaging users with information critically, and encouraging active creation of information (Hall, 2010). Yet, there is surprisingly little 
emphasis given to the public library in the IL literature (Harding, 2008), and studies including public librarians reveal a lack of preparedness and confidence for IL provision (Bruce \& Lampson, 2002; de Jager \& Nassimbeni, 2007; Hart, 2006; Julien \& Hoffman, 2008). These studies also find that CT is considered an important aspect of IL by public librarians, but at the same time show a strong emphasis on the evaluation of sources rather than their content. This framing emphasises the nonfiction content of the library, as a source of explicit information that can be accessed and learned from. The role of fiction, and the role of the public library in promoting $\mathrm{CT}$, is underexplored.

This is mirrored in the wider focus of LIS research, where there has arguably been "a long tradition involving a rationalistic utilitarian more of reading, in contrast to an experiential, emotional mode of reading" (Hampson Lundh et al., 2018, p. 1048). Hampson Lundh and colleagues distinguish the "informational reading" approach, where reading is done to extract facts and specific answers, from "experiential reading" associated with fiction. Informational reading emphasises sources and their usefulness in providing information to be extracted, and as such connects with a fairly simple source-evaluation focused approach to IL. By contrast, experiential reading encompasses the whole process of engagement with the content of a text, and therefore offers a deeper and richer way of evaluating it. Deep engagement with information can be seen as a key predicate in evaluating information (Ward, 2006), and subsequently experiential reading arguably better fits with modern conceptions of IL that emphasise CT. Similarly, arguments have also been made for widening concern in IL beyond intensionally acquired information, but also to consider incidental information (Kohnen \& Saul, 2018); fiction falls into the latter category, as it is not typically sought for specific information it may contain. This suggests a gap in how IL is currently thought about, which research on fiction could help fill. 
There is also a lack of research into public library users engagement with fiction. Studies that do address public library users and fiction collections focus on searching for and selecting fiction texts (Ooi \& Li Liew, 2011; Saarinen \& Vakkari, 2013). When arguments are made for the value of fiction in the public library, it is typically the specific contents of fiction that are appealed to. Public library provision of fiction has been argued to be key in promoting equality across society by providing access to fiction on social justice and diversity themes (Chapman \& Birdi, 2008). In public library patrons, fiction genre has been associated with different personal constructs connected to members of different ethnic groups, genders, and ages (Birdi, 2011). This line of reasoning makes sense, as reading fiction has also been found to be an effective way of bridging differences between social and ethnic groups, reducing bias and stereotyping, and promoting inclusivity (Hakemulder, 2001). Thus diverse fiction collections are likely conducive to more egalitarian attitudes. However, this approach to the value of fiction focuses on the contents of specific kinds of fictional narratives, rather than on the potential value of the act of reading fiction of any kind. It essentially treats fiction with an informational reading approach, as a means of learning about the lives of others, rather than valuing it as gateway into experiential reading that may confer greater ability to step into the lives of others imaginatively and empathetically across contexts.

This approach to fiction is also present in the way it has been used in IL instruction, though with very few cases described. In a blog post, Via Rivera describes using fiction to help students think about ecological issues, arguing that fiction can "help us imagine alternative scenarios, challenge our ideological biases, and allow us to grasp large interconnected networks of ideas" (Via Rivera, 2019); this chimes with understandings of IL and CT, and echoes the findings on fiction reading boosting counterfactual reasoning abilities. Similarly, 
fiction reading has been used in IL instruction around specific subjects such as history (Paterson \& Gamtso, 2019); feminism, and considering future Al developments (DunhamLaGree et al., 2017). However, these approaches again anchor the gains from fiction to the specific subject matter of the reading material. These approaches also utilise fiction in classroom settings, rather than addressing the possible benefits of reading without instruction. This can be somewhat problematic when fiction is used to obtain concrete learning goals. For example Harlan (2019) criticises students who failed to learn the social lessons she designed her use of fiction for, and who used the novel as a self-reflective "mirror", rather than as a "window" through which they might extract the particular social information (Harlan, 2019, p. 6). Harlan's approach to fiction in her instruction is one where "an aesthetic reading experience can be considered an information experience" $(2019$, p. 2). Thus, Harlan crystallises the views that fiction is valuable due to its specific content and subject matter, and that it is valuable as a tool for instruction. Fiction may certainly be useful in this manner, but perhaps not only in this manner. However, the use and understanding of fiction with respect to IL is limited to instructional, informational approaches. Thus, this opens a space for research into whether fiction reading may serve to develop critical thought and IL precisely through its aesthetic, experiential qualities, regardless of the specific information it may contain. For public library workers, who may feel instruction falls outside of their remit, it is interesting to explore the ways engaging with fiction may be beneficial without the need for instructional approaches. Harding (2008) found that librarians in the public library sector are perhaps unwilling to move from a facilitating role aiding patrons in finding sources, towards an instructing role guiding patrons in critiquing the information they find, and argues that more guidance for librarians is 
needed. However, it may the case that aiding patrons into fiction reading can help them to engage in aesthetic reading experiences that could develop their CT capacities.

\section{Summary}

This literature review identified CT as a central aspect of IL. CT encompassed interpersonal and imaginative capacities, such as empathy (Thayer-Bacon, 2000) and counterfactual thinking (Byrne, 2016). These aspects of CT have been linked with increased fiction reading (Black et al., 2017; Mumper \& Gerrig, 2017), and the way that readers are transported into fictional narratives may be driving these benefits (Johnson, 2012). However, there is a current research gap into the relationship between reading fiction and $\mathrm{CT}$, and of fiction reading within IL research more broadly (Hampson Lundh et al., 2018). Additionally, there is a relative lack of IL research in public libraries (Harding, 2008). As public libraries offer access to reading materials, including fiction, they may be enabling patrons to improve their CT. Exploring the potential relationship between reading, particularly fiction, and CT therefore offers a route for practitioners and researchers interested in IL in public libraries to demonstrate the value and need for such reading materials.

\section{Method}

\section{Participant recruitment}

As this study took place during the COVID-19 pandemic, it was conducted entirely online. Self-selecting participants were recruited through social media. Calls for participation specifically asked for readers or bookworms, of fiction and/or nonfiction. Participants who responded were sent the information sheet and consent form, and all consenting participants were included in the study, up until saturation was reached. Saturation was considered to be the point at which no new ideas were identified in an interview, such that 
inviting an additional participant was deemed unlikely to provide novel data (Westbrook, 1994). This yielded a total of 12 participants.

\section{Interviews}

Interviews took place between 18/06/2020 and 12/09/2020, online. Each participant took part in two interview sessions, and each session lasted 30-45 minutes. Interviews had a semi-structured format, with prompt questions and flexibility to pursue participants' unique avenues of thought. Participants were asked about their experiences of reading, including ways they evaluated what they read; their experiences of transportation into the texts they read; their opinions on how reading may relate to $\mathrm{CT}$. In interview 1 , these topics were approached in general. Participants were then asked to pick a text entirely of their choosing to read prior to interview 2, and in interview 2 these topics were revisited with reference to their selected text. Prompt questions were also provided prior to interview 2 so participants knew what to expect. The time period between interviews was flexible to meet participants' needs. Topic sheets for both interviews are available in Appendix A.

Using two separate interviews with each participant permitted a more robust capture of their experiences (Shenton, 2004; Westbrook, 1994). Furthermore, this permitted a subtle difference in emphasis on different scales of reading experience. The first interview captured overall experiences, described by participants with reference to any reading they chose to discuss in the session. The second interview was focused on a specific example of reading, thus providing a narrower framing. As differences have been found in the kinds of media people select for long-term or short-term consumption (Read et al., 1999), framing the interviews to capture both timescales aimed to gather a more holistic sense of participants' reading experiences. 
Whether a text was considered to be fiction or nonfiction was left to participants' judgement. This was in keeping with the intentional approach of defining fiction and nonfiction adopted by this study (Currie, 1985). For example, if one participant described a biography as fiction, but another considered a biography to be nonfiction, these would be treated the way the participants classified them and not re-classified by the researcher.

\section{Analysis}

In analysing the data, an overall move from a high level of detail and granularity towards generalised meaning was taken, enabling an iterative process of sifting and seeking understanding (Williams \& Moser, 2019). A flexible and open approach was taken to initial coding, in keeping with Saldaña's (2016, p.70) "pragmatic eclecticism". An initial round of free coding generated a vast number of codes $(80+)$, allowing for highly detailed capture of immediate interpretations. This was then followed by a whittling down process of seeking synonymous or analogous codes, as a move towards "axial" coding (Williams \& Moser, 2019). For example, initial codes including "understanding others' lives" and "grasping different experiences" were subsumed into one code that could capture these slightly different initial formulations: "Illuminating other life experiences". A final set of 16 codes was arrived at when no further grouping could be accomplished without the loss of important nuance. Next, a "selective" approach was taken to derive overall meaning from grouping codes (Williams \& Moser, 2019); the final codes were divided into 8 overarching categories that captured meaningful commonalities across them. For example, the codes "expanding or shifting mental capacities" and "prompting further thought and action" were distinct from each other, but both captured experiences of change to participants' thinking as a result of reading, and so these were grouped into the category "reading shifts modes of thinking". As part of this categorising process, codes unique to fiction and nonfiction 
descriptions were separated into different categories, as were codes about the experience of transportation, as these groupings enabled the analysis to address the aims of the study. Additionally, codes which captured reading and CT experiences overall were brought together into conceptually cogent categories. For the purposes of this paper, the full results will not be presented. To address the focus of this paper, a subset of 10 codes, and 5 categories, will be discussed in detail.

\section{Validity and reliability}

In order to ensure validity and reliability within the qualitative nature of this study, Guba's (1981) criteria as operationalised by Shenton (2004) were deployed. No purposive sampling was conducted, with participant self-selection and self-identification as readers used to avoid researcher selection bias. Additionally, an iterative questioning approach was used in conducting two interviews with each participant, thus providing a more thorough basis for their responses. The researcher engaged in introspective and methodological reflexivity (Patnaik, 2013); the former by bracketing personal experience as much as possible (Ahern, 1999); the latter by tracking and standardising research procedures. However, it should be noted that this study does not aspire to generalisability; this is a small-scale scoping study laying the ground for potential future work on the experiences of reading and CT.

This study was pre-registered, and preregistration was updated due to the COVID-19 pandemic prior to data collection. The original registration is available here: https://osf.io/3wipr; amendments: https://osf.io/ncp4d.

\section{Participants}

Participants were adult English speakers. All participants self-identified as readers, firstly by answering the call for participation which asked for "readers" and/or "bookworms", and 
secondly by consenting to the selection criteria set out in the participant information sheet which specified "considers themselves to be a reader, reading either fiction or nonfiction regularly." Keeping the definition of being a "reader" open in this way was in keeping with the wider approach adopted by this study permitting participants to define their reading, rather than imposing definition from the researcher. Table 1 shows participant selfidentification in terms of fiction or nonfiction reading, favourite genres or topics, and a description of the text they selected to read for interview 2.

Table 1: Table of Participants

Participant Reader type Preferred genres/topics Chosen text

A

Nonfiction

Current affairs, History,

How-to guides

B

Fiction

Classics, Literary Fiction,

Mystery, Biography

Horror, Historical Fiction,

C Balanced

Literary Fiction History

D

Balanced

Popular Fiction, Graphic

Novels, Fantasy, Science

E

Balanced

Thriller, Science, Biography
Autobiography book

Science article on COVID-19

Mystery novel

Historical fiction novel

Science article on pain 


\begin{tabular}{|c|c|c|c|}
\hline $\mathrm{F}$ & Balanced & $\begin{array}{l}\text { Classics, Fantasy, Sci-fi, } \\
\text { Politics and Economics, }\end{array}$ & $\begin{array}{l}\text { Literary fiction short story } \\
\text { collection }\end{array}$ \\
\hline G & Fiction & $\begin{array}{l}\text { Science } \\
\text { Fantasy, Historical Fiction, } \\
\text { Mystery, Culture }\end{array}$ & Fantasy novel \\
\hline$J$ & Nonfiction & $\begin{array}{l}\text { Classics, History, } \\
\text { Philosophy, Science }\end{array}$ & $\begin{array}{l}\text { Popular science book on } \\
\text { genetics }\end{array}$ \\
\hline $\mathrm{K}$ & Fiction & $\begin{array}{l}\text { Sci-fi, Literary Fiction, } \\
\text { Classics }\end{array}$ & Science fiction novel \\
\hline $\mathrm{L}$ & Nonfiction & $\begin{array}{l}\text { Science, Biography, } \\
\text { Professional }\end{array}$ & Design article on chairs \\
\hline M & Fiction & $\begin{array}{l}\text { Literary Fiction, Fantasy, } \\
\text { Mystery }\end{array}$ & $\begin{array}{l}\text { Opinion article on school } \\
\text { uniforms }\end{array}$ \\
\hline $\mathrm{N}$ & Nonfiction & $\begin{array}{l}\text { Fantasy, Professional, } \\
\text { History, Biography, Science }\end{array}$ & Short story collection \\
\hline
\end{tabular}

Note: "I" was omitted to avoid confusion with the pronoun, " $H$ " was omitted to avoid confusion with the researchers' initials in the transcripts. 


\section{Results}

The results are presented by categories, rather than emphasising codes, as these give a more holistic way of presenting the data with reference to the study aims. Table 2 provides an overview of the categories and the codes that comprised them. The first three categories relate to overall reading experiences, with the following two categories specifically addressing fiction and nonfiction.

Table 2: Summary of codes and categories

\begin{tabular}{ll}
\hline Code & Category \\
\hline
\end{tabular}

Expanding or shifting mental capacities

Reading shifts modes of thinking

Prompting further thought and action

Reading as widening exposure

Reading prompts $\mathrm{CT}$ circuitously

Reading material contains thinking prompts

Narrative transportation is active engagement

Narrative transportation integrates CT

Narrative transportation is connection-making into reading

Illuminating other life experiences

Fiction provides understanding of the

Source of social or historical information real world

Reading to gain information

Explicit opinions and questions directly prompt

Nonfiction provides direct information

CT 


\section{Reading shifts modes of thinking}

Reading was described as a driver of change, both in terms of thinking processes as seen in the code expanding or shifting mental capacities, and in terms of altering trajectories in prompting further thought and action. These codes encompassed immediate as well as longer term changes.

The belief that reading helped mental development was widespread among participants: "It helped the brain evolve" (Participant A) and "allows you to broaden your mind" (Participant C). However, there were deeper and more concrete ways this was experienced also. Participants described taking on structures for thinking from the material they read, for example in taking on the investigators' approaches from mystery novels, or:

\footnotetext{
"Anyway, so I really liked the problem-solving, engineering, mindset that was portrayed in the novel. And so I found myself adopting it I guess. Trying to think like those characters. So maybe I was learning a way of thinking critically, by having it modelled in those characters. Like it was quite aspirational. But yeah, what I'm getting at, is that for me I think everything I read gets under my skin. It colours my thinking. Whatever it is." Participant K
}

These ways of adopting thinking approaches were often connected to fiction as in this example, and participants described characters as models whose thinking they could actively learn from. Nonfiction was also seen as a driver of mind-broadening, but without this character-driven thought process adoption.

Participants also described ways that the experience of reading altered their thinking approaches more concretely. For example, Participant E on reading Harry Belafonte's autobiography: 
"It made me think critically about the power of celebrity and it's place in a political campaign. And to the point that possibly I've reversed my view completely [...] So I completely sort of changed my cynical views on the role of that. And the other thing that I thought long and hard about was how he maintained such a high level of motivation over a very long time, because obviously there would have been so many setbacks, so many knocks, so many different factions saying things should be done in a different way. How hard it is to just know that what you're doing is correct, and stick with that, and not be swayed by other strong personalities." Participant $E$

In this example, Participant $E$ both changes a specific opinion on the utility of celebrity status, and reflects on a more general approach to dealing with challenges. This demonstrates how reading could provide both very specific change, but also more subtle personally reflective shifts. Participants also pointed to changes in behaviour resulting from reading experiences:

"I think probably the story that impacted me the most was this story about the woman's grief around her child. And I think that, um, I found myself thinking about it [...] Like for the couple of days afterwards I was very aware of people around me, and kind of the emotions they were feeling. And there was actually a, we lost a colleague a few days ago, he had a heart attack at 41 at work, and people's grief and they're processing the grief - that made me think of the story in a different way. [...] So I was like, that's something I'Il think of in the future." Participant N

Participant N's reading experience led to change in perspective on grief, and prompted different behaviour at work, with ongoing longer-term impact. It is notable that these participants describe change arising from the experience of reading, not only as a result of information taken from the text. 


\section{Reading material contains critical thinking prompts}

The content of the texts participants read was important to their CT. Firstly, the code reading as widening exposure characterised ways reading could provide access to novel and surprising ideas and experiences. Secondly, the code reading prompts CT circuitously was concerned with the way that information or opinion could be delivered in the reading experience.

Broadening minds, breaking through barriers, and taking readers out of their comfort zones were commonly articulated by participants as ways that reading promotes CT. However, for many participants this required material that contained new perspectives or approaches:
"I guess there's always a risk of getting into a bubble, you know, like, reading always the same type of things, the same subject matter from the same perspectives. And if you did that, that would definitely influence your thinking habits, in the sense of narrowing them down I think. And conversely, I think if you read broadly - so on many different subjects from many different points of view - then that's going to broaden out your thinking too." Participant J

Indeed, books gifted or recommended by others were particularly valued by participants as broadening reading and subsequently thinking. Yet, there was also acknowledgement that all reading material had some novelty:

\footnotetext{
"it'd be very hard to always be picking up a book that met all your expectations, that would be something that always prescribed to the exact same beliefs as yourself. I think most people are going to think differently to you about something [...] But chances are if you're using different authors, you're going to hit something which then makes you question something, even if it's something small. So I
} 
think it'd be very hard to not think critically, I suppose." Participant

$\mathrm{N}$

In this way, there was a sense that all reading would prompt $\mathrm{CT}$, but a breadth of reading would do so to the greatest extent.

Additionally, the authors of texts were also themselves prompts for critical thought. Nonfiction authors were assessed for their credentials, with judgments made on their authority and credibility with respect to the subject matter of the text. However, evaluations about fiction authors were more complex:
"When you're writing fiction I think you have to be able to have a bit of distance. An author will have their own values and biases which will probably come out in in their work, but we have to think about to what extent do we take things in that book as an author's genuine views, for example, like if they use racist language is that a reflection on the author as a person, rather than a character they're creating? I guess it's about having a little distance between a story and a real world impact. But then to deny that stories do have a real world impact isn't good either. People read them in the real world." Participant B

In this example, there is a layer of complexity in decoding the fiction authors' views in those of their characters. There is also a further complication in how the fictional work can relate to reality.

The prompting of critical thought could arise from the emotional valence of the reading experience. For example, the pleasurable curiosity of reading a fictional narrative could lead to evaluations and predictions as part of the enjoyment of the reading: "it's very much kind of like a game" (Participant G). When it came to nonfiction, a similar form of enjoyment 
could be aroused in the tone of the text, which could also give rise to $\mathrm{CT}$, for example when reading A. A. Gill:
"it's a bit tongue-in-cheek. How much it's tongue-in-cheek I'm not quite sure [...] He goes on a rant about the National Trust - and who can hate the National Trust? - but then maybe he makes some valid points about land ownership." Participant B

Here, the argument is packaged in a written style that makes it enjoyable to read, which delivers the ideas to be thought about. This delivery of ideas through the reading experience, with its particular emotional character, was pointed to by participants as a special means circuitous CT prompting:
"So by reading more, I think that's a good way to build up discomfort, I mean build up resistance, like tolerance of it. Maybe it's a safe way of doing it, and non-aggressive way. Because like, in the pub if somebody says something you disagree with you might want to avoid an aggressive loud argument, which would be extremely uncomfortable. You don't want confrontation, normally. But if you're reading a book and you disagree with the author's argument, well that's not nearly as uncomfortable, isn't it." Participant J

In both fiction and nonfiction examples, therefore, participants articulated ways that that reading could bypass defences, offering material for CT in a "more sideways way" (Participant N). However, it was in fiction examples that the code reading prompts $C T$ circuitously was most developed:

\footnotetext{
"And I think the Discworld is a really good vehicle to deliver those observations in. Because if it's sets in the real world, it will probably be a lot more controversial. I think the humour is a key part of it as
} 
well - and you wouldn't be able to make it as funny. And you also wouldn't have the joy of reading it and being like, 'oh, okay, that's what he's paralleling here', because it'd be too obviously delivered. It's got all that layer of subtlety where, you know, he's parodying something in the real world, but you work out what it is as you read [...] I think if something makes you laugh, you're a bit more open to it. Rather than if I was reading this and I was someone who maybe didn't have those values, I think I'd be less inclined to get defensive reading Pratchett, than reading a book set in the real world that clearly attacks the things I hold close to my heart." Participant G

Here, participant $G$ points to the transformation of the real that fiction necessitates, and how this both increases openness, bypasses defences, and also deepens CT in introducing subtlety and complexity. This suggests both an increased accessibility, and an increased necessity for $\mathrm{CT}$ in the fiction reading experience.

\section{Narrative transportation integrates CT into reading}

For participants in this study, the experience of being transported into a text was one of thinking and evaluating integrated into the reading experience. The codes narrative transportation is active engagement and narrative transportation is connection-making depict how this evaluative, immersive, transported reading took place.

Being transported by reading was active, requiring attention and energy, as well as creative engagement. For instance, Participant C identified times of day "when I suppose I can really be creative, my mind's creative" as the best times to read, in order to be transported. Transportation was an experience connected with problem-solving and critiquing as one read, such that CT did not break the flow the reading experience but in fact supported it: 
"I think it's intrinsic. I think you're doing that during the process of reading. Otherwise, I don't think you would feel as much when reading. You wouldn't be so invested in the book if you weren't making these judgments and thought processes while you read. You do it at the time that you are reading." Participant D

In this way, the evaluative aspects of being transported formed a part of the pleasure of the reading experience, and maintained attention and immersion, with participants describing how CT "gathered pace" (Participant E) during reading and helped "get into more depth" (Participant J).

The kinds of evaluations made in highly transported reading engagement were very diverse. They were characterised by a connection-making experience. This could be building connections internal to the text at hand, to make the reading experience "connect up as a whole" (Participant J). Some connections were made imaginatively beyond the text, e.g. Participant $\mathrm{K}$ described imagining additional characters in the story line of a novel. Often, connections were made between one's own reflections and experiences, and those of characters in the text:

\footnotetext{
"So, obviously very different to my life, but also there's things I'm quite interested in and can relate to, about women's careers, having partners and marriage and that sort of thing - being in my early $30 \mathrm{~s}$ these things are quite relevant, and things that my friends and I are kind of a bit conscious of. [...] There's some sort of sense of maybe not quite identifying, but definitely things that prompted me to think about my experiences." Participant B
}

This highly reflective and self-evaluative connection making was most common with fiction reading experiences. Additionally, in very transported reading connections were also drawn 
between participants' physical locations and the settings of their texts. Further connections were also made with a future-oriented focus:

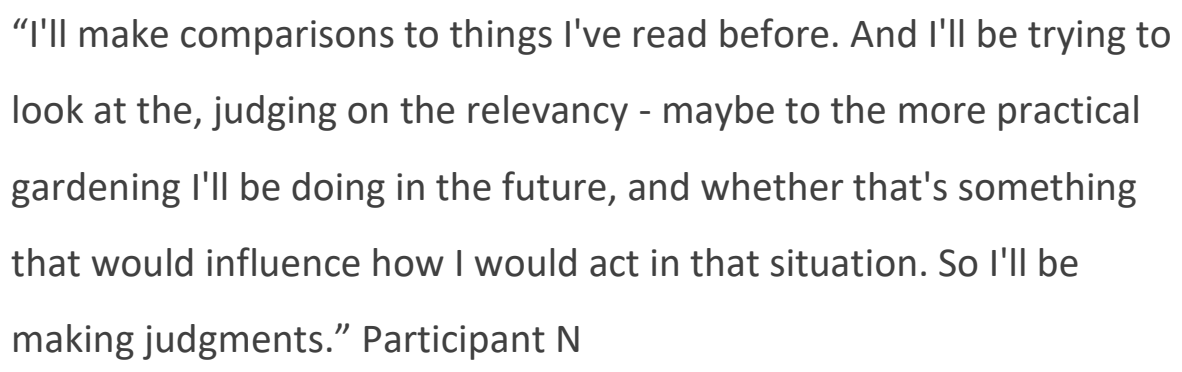

Crucially, these were all described as immediate experiences of thinking and evaluating, not setting the text aside and breaking the transportation into the reading experience, but concurrent with it.

Finally, this integrative transported state in which reading experiences intermingled with critical thought was described in a multi-layered way. Participants articulated conscious experiences of connecting particular pieces of information as they read. But they also felt these reading experiences fed deeper undercurrents and built underlying foundations: “I almost think reading is like the real time example of almost how your own brain connects" (Participant D). In this sense, reading and CT could not be disentangled in the transported connective state.

\section{Fiction provides understanding of the real world}

In addition to the ways that fiction and nonfiction were differently represented within the previous categories, there were also codes that uniquely captured fiction or nonfiction reading experiences. This category encapsulates the fiction codes of illuminating other life experiences, and source of social or historical information. Through these two strands, participants' fiction reading experiences gave rise to deep and complex understandings of the world and other lives. 
Participants described fiction as a means of understanding lives very different to their own: “I'll never know what it's like to be a gay man in Afghanistan, that will never be an experience I have, but it doesn't mean I couldn't read about it, and try and think about what might that be like." (Participant B). An essential element of this was the way fiction provided an experience in another's life, rather than simply giving information about it: "I'd say if you read fiction, as you go along with character development in fictional works, critically you might see human behaviour as the sum of all its parts, because you've witnessed that when you read fiction." (Participant D). This meant that the fictional experience had to be followed through in a time-extended manner, progressing through the narrative journey in order to reach this sense of a "sum of all its parts" that participant D describes. This was actively compared to the way nonfiction offers isolated time-slices:

\footnotetext{
"Because when you see news stories, it's always the aftermath. It's always a revision of what's happened and it's never as it's happening. Whereas a lot of her stories they're talking about it as if it's happening now, it's in the present it's current. [...] you get more of a human story, you get more of the kind of the struggle behind it. And the worries that both the child and the parents have both when they're being captive and when they're being released and all this kind of stuff that you don't necessarily get from an interview with the victim afterwards, or you don't get that from the news reporter standing outside the house giving you the facts of what has happened in their words. And so it definitely gives you more of it, I think a sympathetic view towards the victim while it's happening, instead of the aftermath." (Participant M)
}

This places the gradual, time-extended experience of fiction reading at the fore in terms of its power. Similarly to these descriptions of learning about characters' lives, the fictional 
experience was also characterised as delivering insights into regional and historical contexts. Participants also integrated these insights into self-reflections, comparing their own lives, social contexts, and histories to those they encountered in fiction.

Finally, there was a special relationship between this learning from fictional material, and CT. This lay in the issues of veracity and authenticity that the fictional sources entailed:

"And what I think is a really interesting question, is about the legitimacy of an author's work. So should authors only write about things that they have direct experience of on some level? Is it legitimate if I were to write a story about an Aboriginal Australian? Could I put myself in their shoes and write a novel? Would that be inappropriate? Are stories about, yes just telling stories, but what role do they play in people's understanding of the world?" Participant B

This is related to similar issues that were raised by fiction under the category reading material contains critical thinking prompts, but here fiction uniquely triggers $\mathrm{CT}$ by giving such intimate access to other lived experiences, such that the authors' relation to those experiences is highlighted for critical questioning.

\section{Nonfiction provides direct information}

Nonfiction reading was characterised by participants in the codes reading to gain information and explicit opinions and questions directly prompt CT. Participants sought nonfiction for concrete information needs, and valued it for its directness as an explicit starter for CT.

Nonfiction texts were characterised both in terms of utility, and in terms of enjoyment, with a sense of arising empowerment from the reading experience: "It's about educating 
yourself. You can have a background, go a crap school and that, but you can read" (Participant L). The empowerment offered by nonfiction came from its benefits in expanding one's knowledge base, and this knowledge base in turn formed the foundation for CT:

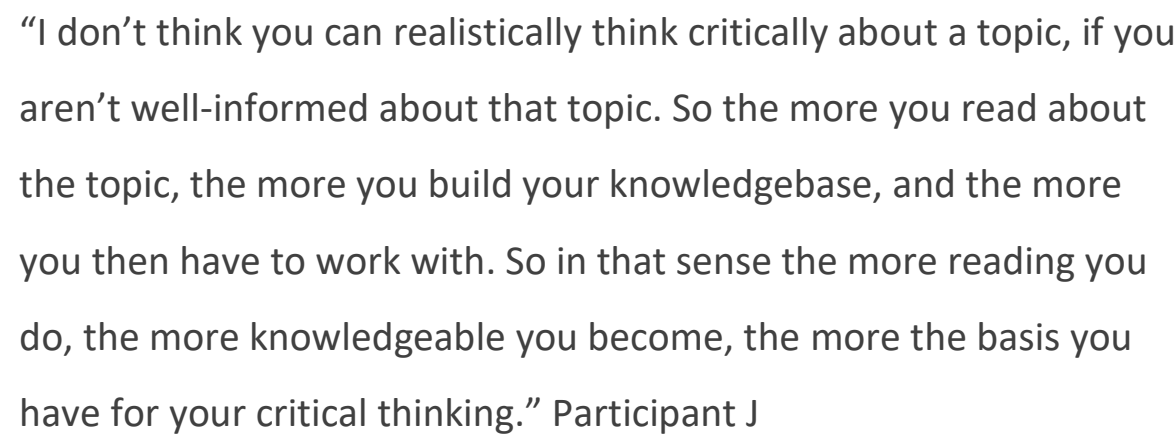

This formed a cycle in participants' descriptions, as they read nonfiction in order to obtain information, and that information provided a stronger basis from which to think critically, which in turn would identify further information needs.

The way that nonfictional information content was experienced during reading was also an important element in the relationship with CT. Participants described how nonfiction authors' opinions are typically made explicit, as are their prior beliefs and contexts, in contrast with fiction where the authors' position is obfuscated. This nonfiction directness of argument and clarity of author background gave a sure footing for evaluations. Likewise, reference list in nonfiction books offered confidence in judging their validity. Finally, the clear way that questions were posed directly to the reader in nonfiction was seen as a driver of $\mathrm{CT}$ :

"I think I might recommend that one. Sapiens. It makes you question a lot of things, the history of man, our place in the universe, our belief systems, the things that we believe in, are they real? Are they tangible? No, they're not. Why do we believe when we can't even see them? Why do we believe in them so much? Yeah. It's a 
fascinating read, because it covers lots of different things. I don't know if I came out with any conclusions. But yeah, very, very good read." (Participant E)

This indicates how nonfiction was also sought for the questions it raised, not always merely for answers.

\section{Discussion}

This discussion firstly reflects upon the research questions that guided this study, relating the findings to these. Next, study findings are compared and contrasted with the previous literature, indicating support for previous findings as well as areas of extension beyond prior knowledge. Following this, the value of reading material is addressed in terms of type, as well as in the context of public library provision. Finally, study limitations are addressed.

This study identified ways in which the experience of reading was connected with $\mathrm{CT}$, that offer some answers to the research questions presented in the introduction. Firstly, to answer question a. In what ways do readers experience an influence of what they read on how they think critically?, reading was found to shift and build mental capacities and thinking approaches, feeding into alterations in beliefs, ways of thinking, and behaviour. Reading material was identified as a prompt for CT in diverse ways, by broadening exposure to different ideas, experiences, and viewpoints, but also in its power to trigger CT in subtle and circuitous ways that were experienced as safer and less uncomfortable than real-life engagements. These findings offer insight into the relationship between reading and CT experiences overall, and also form a ground for comparison from which differences between fiction and nonfiction experience can be traced. 
Addressing question $\mathrm{b}$. In what ways do readers' experiences pertaining to question a. differ between fiction and nonfiction reading? Are there any unique associations for fiction?, fiction and nonfiction were found to play different roles in these relationships. Firstly addressing fiction reading, this did have unique associations with $\mathrm{CT}$, as it could shift thinking approaches by offering models in the characters presented which readers actively learned from and adopted in their own thinking. Fictional material was also most strongly connected with the subtle and circuitous ways that reading could drive CT, as it offered pleasurable and otherworldly contexts for important issues, and complicated the position of the author. Furthermore, beyond these ways that fiction was represented in the categories that described reading experiences in general, there were also unique categories arising from participants' descriptions of fiction and nonfiction reading. Fiction reading experiences were associated with deep understandings of the real world, both in terms of providing access to lived experiences, and in terms of illuminating social and historical contexts. It was the time-extended journey through the experience of the fictional narrative that participants' identified as offering these gains, in contrast to nonfiction post-facto reporting. The way fiction material complicated issues of veracity and obfuscated the author's position was also highlighted as promoting further critical thought and complex evaluation.

These experiences of fiction reading linked to $\mathrm{CT}$ can be furthermore emphasised when we consider how differently participants experienced nonfiction in relation to CT. By contrast to the circuitous nature of fiction, it was the very explicit and direct nature of information offered in nonfiction that participants saw as its means of prompting CT, in directly providing authors credentials, and directly raising questions. However, within nonfiction reading the experience itself was important also, as seen in the example of an argument delivered with humour and irony, giving an emotional valence to the way it was received 
that also allowed a bypassing of defences. This suggests that in all reading, the aesthetic experience and not merely the informational content are important for CT. Overall, by identifying differences in how participants experienced their nonfiction and fiction reading connected to $\mathrm{CT}$, this study enriches existing research focused on nonfiction reading, and furthermore demonstrates a unique role of fiction in CT.

Finally, addressing question c. How do readers' experiences of transportation while reading relate to the ways in which they think critically about a text?, the experience narrative transportation which immersed readers into texts was found to integrate evaluative, critical thought into the reading experience. These transported reading experiences were characterised by participants as highly active, connection-making processes through which they evaluated and integrated the text with their own experiences and contexts. As such, the experience of reading was also an experience of thinking critically.

\section{Relation to the literature}

The findings of this study align with previous research showing readers of fiction develop empathic capacities (Mar et al., 2009), and learn about the lives of people very different from themselves (Hakemulder, 2001). The ways participants described engaging with characters, and broadening their mind as a result, strongly echo this. As such, this study adds further evidence to arguments for public library provision of diverse texts as a means of increasing social inclusion (Chapman \& Birdi, 2008). However, participants in this study described engaging with fictional characters as providing more than this understanding of different lives. They also modelled their own thinking approaches on those displayed by characters. Participants also gained reflective and personal insights from their fiction reading, and these reflections were highly transformative, showing the value of fiction as a 
"mirror" and not just a "window" (Harlan, 2019). This suggests that fiction can provide value both in broadening exposure, and in deepening reflection.

Another key benefit of fiction reading found in previous research has been increased counterfactual reasoning (Black et al., 2017). This study also contributes findings connecting fiction reading with broadening imaginative capacities, to consider different possibilities, as participants articulated ways in which their reading experiences engaged them in alternate scenarios and ideas which might have been uncomfortable in more direct confrontation. Furthermore, it was also the unknown in fiction that promoted $\mathrm{CT}$, and by being unknown triggered thinking through different possibilities to fill that gap; this can be seen the way participants imagined how the author could possibly relate to the opinions of their characters, or how their lived experiences could inform those in the narrative.

Throughout the findings of this study, the experience of reading has been shown to be essential in its relationship with $\mathrm{CT}$, not merely the informational contents of the texts read. The transported, immersed experience of reading was found to contain and indeed entail critical thought, with connection-making within texts and also between the read material and participants' lives and surroundings. As narrative transportation has been previously found to be a driver of the power of fiction to increase empathy (Johnson, 2012), and as the simulative experience of fiction reading is argued to be what enables the training of abilities (Oatley, 2011), the findings of this study are in keeping with these previous research findings. Furthermore, it was the journey through the fictional narrative, in which each moment is experienced across the time-span of the story, that was identified as providing indepth understandings, in contrast with the simpler post-facto reporting of nonfiction that could not offer such depth of engagement and fullness of evaluation. Therefore, the findings 
from this study point to the nature of the fiction reading experience, not only the specific contents of fiction, as a driver of CT.

Finally, these findings on fiction can be understood as distinctive from those on nonfiction, highlighting fiction's relationship with CT as an area worth investigating further, while at the same time furthering existing understandings of the value of nonfiction. As nonfiction was found to be valued by participants for its direct and clear informational content, this supports the use of nonfiction in "informational reading" approaches (Hampson Lundh et. al., 2018). However, nonfiction was also experienced in transported and aesthetic ways, and these experiences (not only the information extracted) were valued by participants. This finding echoes IL perspectives arguing that deep engagement with information is needed to evaluate it (Ward, 2006). Furthermore, as participants did not always read nonfiction in order to extract information, but also for the experience, and yet came to connect nonfiction with CT through its informational content, this supports IL including incidental information (Kohnen \& Saul, 2018); even when embarking on reading without a motivating information need, the information incidentally discovered in the nonfiction text was what participants felt fed their CT.

\section{The value of reading material}

Participants in this study described reading a plethora of reading materials, and were asked questions about what types of reading material they considered to be important for $\mathrm{CT}$. It is notable that participants did not point to more or less value in reading fiction of different types. As some genres, notably romance, can be perceived as having lower value (Veros, 2020), it could have been expected that participants would feel this type of material is less conducive to critical thoughts. Similarly, literary fiction is often separated from popular 
fiction, and argued to confer benefits the latter does not (Oatley, 2011); yet participants did not specify that texts must be literary in order to prompt CT. Indeed, many of the examples given by participants of works that promote CT (such as Terry Pratchett's fantasy novels), were resolutely popular fiction works. This suggests that librarians who make quality judgements in their collection selection processes favouring some genres and avoiding others (Veros, 2020), ought to rethink their assumptions, as readers can find avenues for critical thought in a plethora of fictional texts. Similarly, while participants did judge the quality of nonfiction texts with reference to markers of authority, they included very diverse examples (e.g. "for dummies" books, satirical essays, how-to guides), and emphasised the need for broad reading. This implies value in a wide range of both fiction and nonfiction material.

This study offers an indication that providing access to reading material, and particularly fictional material, is valuable for readers' CT. For public librarians, this suggests that their work as facilitators guiding patrons to access materials, even without providing any instruction (Harding, 2008), can be beneficial. Indeed, participants specifically pointed to broad reading as valuable, and suggested that book recommendations and gifts of books could play a special role in broadening their perspectives by being outside of their comfort zone. Perhaps exposure to diverse public library fiction collections, with access to librarians' recommendations and showcased books, could similarly help broaden reading habits and thus help broaden CT approaches. Given the high importance of CT for society (Mason et al., 2018), and the argued role of public libraries in social and democratic engagement (Hall, 2010), this is an area worthy of further research. 


\section{Limitations and future directions}

The participants in this study self-identified as readers, and it is essential to interpret these results as pertaining to readers, not to a wider population. It would be interesting to conduct similar interviews with participants who do not view reading as part of their identity, and for whom it is perhaps less of a common activity; very different experiences of reading and its relationship with $\mathrm{CT}$ might be found in people who have different relationships with reading. Additionally, using an intentional approach (Currie, 1985) and having participants identify texts as fiction or nonfiction limits these findings to these participants' specific understandings of these categories; wider participant groups may identify some texts differently.

Additionally, participant recruitment was conducted online, and the interviews took place online, meaning the sampled participants were internet users with a certain level of technological aptitude and engagement. As the study took place during the COVID-19 pandemic, recruiting participants in physical library spaces was not possible. However, many readers and wider public library users are not users of digital technologies (Serafino, 2019). There may be differences between the ways this study sample experienced reading and CT, and wider groups. As participant demographic information was not collected, these findings furthermore cannot inform understandings of groups differences in CT and reading. More broadly, this study is not intended to provide generalisable findings. This was a small scale, in-depth study establishing an initial insight into how the experience of reading could relate to CT. Further research is needed to further explore this relationship. 


\section{Conclusion}

This study found that for readers, reading experiences were connected with ways of thinking critically. Reading both fiction and nonfiction was described as broadening minds and shifting modes of thinking, and prompting critical thought in a diverse range of ways. Fiction had unique associations with different ways of changes one's thinking approaches, and could prompt CT in subtle and circuitous ways. Furthermore, fiction was described as giving deep and rich insights into the real world, and engaging readers in fluid, timeextended, reflective thought. Nonfiction by contrast was valued for its directness and clarity of provenance. The experience of being transported into reading was inherently evaluative, integrating critical thought into the reading experience, as readers' built connections and integrated what they read into their settings and experiences. These findings show that different reading materials are related to experiences of $\mathrm{CT}$ in different ways, and that fiction reading does have a unique association with particular ways of thinking critically. These ways in which reading was found to feed into critical thought imply a value in proving reading materials, especially fiction, as a means of enabling such evaluative engagement across society. This implies that public library provision of reading material is valuable not only for entertainment, but also for enrichment of thinking capacities, therefore indicating a short-sightedness in reducing public library funding. Furthermore, the ways that readers experienced impacts on their CT from what they read by themselves, without instruction, suggest that the promotion of reading without a requirement for targeted focus on its contents or for classroom instruction is valuable. These findings offer an indication that focusing on fiction in IL research practice would be a worthwhile endeavour. 


\section{References}

Ahern, K. J. (1999). Ten tips for reflexive bracketing. Qualitative Health Research, 9(3), 407411. https://doi.org/10.1177/104973239900900309

Bailin, S. (1987). Critical and creative thinking. Informal Logic, 9(1), 23-30. https://doi.org/10.22329/il.v9i1.2656

Batchelor, O. (2017). Getting out the truth: The role of libraries in the fight against fake news. Reference Services Review, 45(2), 143-148. https://doi.org/10.1108/RSR-032017-0006

Birdi B (2011) Investigating fiction reader characteristics using personal construct theory. Aslib Proceedings 63(2-3): 275-294. DOI: http://dx.doi.org/10.1108/00012531111135709.

Black, J. E., Capps, S. C., \& Barnes, J. L. (2017). Fiction, genre exposure, and moral reality. Psychology of Aesthetics, Creativity, and the Arts. https://doi.org/10.1037/aca0000116

Boell, S. K., \& Cecez-Kecmanovic, D. (2010). A hermeneutic approach for conducting literature reviews and literature searches. Australian Academic \& Research Libraries, 41(2), 129-144. https://doi.org/10.1080/00048623.2010.10721450

Bruce, H., \& Lampson, M. (2002). Information professionals as agents for information literacy. Education for Information, 20(2), 81-106. Ils.

Byrne, R. M. J. (2016). Counterfactual thought. Annual Review of Psychology, 67(1), 135157. https://doi.org/10.1146/annurev-psych-122414-033249

Chapman, E., \& Birdi, B. (2008). Fiction for all. Public Library Journal, 23(1), 8-11.

CILIP. (2017). Information literacy. https://archive.cilip.org.uk/research/topics/informationliteracy 
CILIP. (2018). ILG launch new CILIP information literacy definition. https://infolit.org.uk/newil-definition/

Currie, G. (1985). What is fiction? The Journal of Aesthetics and Art Criticism, 43(4), 385392. JSTOR. https://doi.org/10.2307/429900

D’Angelo, B. J. (2001). Using source analysis to promote critical thinking. Research Strategies, 18(4), 303-309.

de Jager, K., \& Nassimbeni, M. (2007). Information literacy in practice: Engaging public library workers in rural South Africa. IFLA Journal, 33(4), 313-322. https://doi.org/10.1177/0340035207086057

Dumitru, D. (2019). Creating meaning: The importance of arts, humanities and culture for critical thinking development. Studies in Higher Education, 44(5), 870-879. https://doi.org/10.1080/03075079.2019.1586345

Dunham-LaGree, C., Chibnall, D., \& Becker, S. (2017, May 19). The power of stories: Using fiction \& nonfiction to develop information literacy skills. lowa Library Association Association of College and Research Libraries Conference. https://ir.uiowa.edu/ilaacrl_conference/2017/spring/2

Ennis, R. H. (2016). Definition: A three-dimensional analysis with bearing on key concepts. OSSA Conference Archive, 115. https://scholar.uwindsor.ca/ossaarchive/OSSA11/papersandcommentaries/105?utm _source=scholar.uwindsor.ca\%2Fossaarchive\%2FOSSA11\%2Fpapersandcommentarie s\%2F105\&utm_medium=PDF\&utm_campaign=PDFCoverPages

Facione, P. A. (1990). Critical thinking: A statement of expert consensus for purposes of educational assessment and instruction. Research findings and recommendations. https://eric.ed.gov/?id=ED315423 
Flood, A. (2020, December 4). UK's public libraries record another year of cuts, with yet more on the way. The Guardian. http://www.theguardian.com/books/2020/dec/04/ukspublic-libraries-record-another-year-of-cuts-with-yet-more-on-the-way

Fong, K., Mullin, J. B., \& Mar, R. A. (2013). What you read matters: The role of fiction genre in predicting interpersonal sensitivity. Psychology of Aesthetics, Creativity, and the Arts, 7(4), 370-376. https://doi.org/10.1037/a0034084

Friend, S. (2008). Imagining fact and fiction. In K. Stock \& K. Thomson-Jones (Eds.), New waves in aesthetics (pp. 150-169). Palgrave Macmillan.

Frímannsson, G. H. (2016). Reasons and normativity in critical thinking. Studier i Pædagogisk Filosofi, 4(1), 3. https://doi.org/10.7146/spf.v4i1.18594

Gainer, J. (2012). Critical Thinking: Foundational for Digital Literacies and Democracy. Journal of Adolescent \& Adult Literacy, 56(1), 14-17. https://doi.org/10.1002/JAAL.00096

Gerrig, R. J. (1993). Experiencing narrative worlds: On the psychological activities of reading. Yale University Press: New Haven, CT. https://doi.org/10.2307/j.ctt1dr37cb

Guba, Egon G. (1981). Criteria for assessing the trustworthiness of naturalistic inquiries. Educational Communication and Technology, 29(2), 75-91.

Hakemulder, J. (2001). How to make alle menschen bruder: Literature in a multicultural and multiform society. In G. Steen, D. H. Schram, \& E. Ibsch (Eds.), The psychology and sociology of literature: In honor of Elrud Ibsch (pp. 225-242). John Benjamins.

Hall, R. (2010). Public praxis: A vision for critical information literacy in public libraries. Public Library Quarterly, 29(2), 162-175. https://doi.org/10.1080/01616841003776383 
Hampson Lundh, A., Dolatkhah, M., \& Limberg, L. (2018). From informational reading to information literacy. Journal of Documentation, 74(5), 1042-1052. https://doi.org/10.1108/JD-11-2017-0156

Harding, J. (2008). Information literacy and the public library: We've talked the talk, but are we walking the walk? Australian Library Journal, 57(3), 274-294.

Harlan, M. A. (2019). Fiction as information: A look at reading as information source. International Association of School Librarianship. Selected Papers from the ... Annual Conference, 1-10. ProQuest Central; Social Science Premium Collection. https://search.proquest.com/scholarly-journals/fiction-as-information-look-atreading-source/docview/2343150585/se-2 ?accountid=14511

Hart, G. (2006). Public librarians and information literacy education: Views from Mpumalanga Province. South African Journal of Libraries \& Information Science, 72(3), 172-184.

Johnson, D. R. (2012). Transportation into a story increases empathy, prosocial behavior, and perceptual bias toward fearful expressions. Personality and Individual Differences, 52(2), 150-155. https://doi.org/10.1016/j.paid.2011.10.005

Julien, H., \& Hoffman, C. (2008). Information literacy training in Canada's public libraries. The Library Quarterly, 78(3), 19-41. https://doi.org/10.1086/523908

Kohnen, A. M., \& Saul, E. W. (2018). Information literacy in the internet age: Making space for students' intentional and incidental knowledge. Journal of Adolescent \& Adult Literacy, 61(6), 671-679. https://doi.org/10.1002/jaal.734

Kuhn, D. (2019). Critical thinking as discourse. Human Development, 62(3), 146-164. https://doi.org/10.1159/000500171 
Machete, P., \& Turpin, M. (2020). The use of critical thinking to identify fake news: A systematic literature review. In M. Hattingh, M. Matthee, H. Smuts, I. Pappas, Y. K. Dwivedi, \& M. Mäntymäki (Eds.), Responsible Design, Implementation and Use of Information and Communication Technology (Vol. 12067, pp. 235-246). Springer International Publishing.

Mar, R. A., Djikic, M., \& Oatley, K. (2008). Effects of reading on knowledge, social abilities, and selfhood. In S. Zyngier, M. Bortolussi, A. Chesnokova, \& J. Auracher (Eds.), Directions in empirical studies in literature: In honor of Willie van Peer (pp. 127-137). Benjamins.

Mar, R. A., Oatley, K., Hirsh, J., dela Paz, J., \& Peterson, J. B. (2006). Bookworms versus nerds: Exposure to fiction versus non-fiction, divergent associations with social ability, and the simulation of fictional social worlds. Journal of Research in Personality, 40, 694-712. https://doi.org/10.1016/j.jrp.2005.08.002

Mar, R. A., Oatley, K., \& Peterson, J. B. (2009). Exploring the link between reading fiction and empathy: Ruling out individual differences and examining outcomes. Communications, 34(4), 407-428. https://doi.org/10.1515/COMM.2009.025

Mason, L., Krutka, D., \& Stoddard, J. (2018). Media literacy, democracy, and the challenge of fake news. Journal of Media Literacy Education, 10(2), 1-10. https://doi.org/10.23860/JMLE-2018-10-2-1

McNicol, S., \& Dalton, P. (2003). Broadening perspectives on the learning process in public libraries. New Review of Libraries \& Lifelong Learning, 4(1), 27-43.

Mumper, M. L., \& Gerrig, R. J. (2017). Leisure reading and social cognition: A meta-analysis. Psychology of Aesthetics, Creativity, and the Arts, 11, 109-120. https://doi.org/10.1037/aca0000089 
Oatley, K. (2011). Such stuff as dreams: The psychology of fiction. Wiley-Blackwell.

Ooi, K., \& Li Liew, C. (2011). Selecting fiction as part of everyday life information seeking. Journal of Documentation, 67(5), 748-772. https://doi.org/10.1108/00220411111164655

Paterson, S., \& Gamtso, C. (2019). Excavating visual texts: Information literacy, critical thinking, and the graphic novel in the crime fiction classroom. In O. Miller \& S. Grimm (Eds.), Comics and Critical Librarianship: Reframing the Narrative in Academic Libraries (pp. 275-289). Library Juice Press. https://scholars.unh.edu/unhmlibrary_pub/19

Patnaik, E. (2013). Reflexivity: Situating the researcher in qualitative research. Humanities and Social Science Studies, 2(2), 98-106.

Paul, R. (1981). Teaching critical thinking in the 'Strong' sense: A focus on self-deception, world views, and a dialectical mode of analysis. Informal Logic, 4(2). https://doi.org/10.22329/il.v4i2.2766

Paul, R. (1987). Dialogical thinking: Critical thought essential to the acquisition of rational knowledge and passions. In J. B. Baron \& R. J. Sternberg (Eds.), Teaching thinking skills: Theory and practice (pp. 127-148). W. H. Freeman and Company.

Read, D., Loewenstein, G., \& Kalyanaraman, S. (1999). Mixing virtue and vice: Combining the immediacy effect and the diversification heuristic. Journal of Behavioral Decision Making, 12(4), 257-273. https://doi.org/10.1002/(SICI)1099-

0771(199912)12:4<257::AID-BDM327>3.0.CO;2-6

Root, R. L. (2004). Variations on a theme of putting nonfiction in its place. Pedagogy, 4(2), 289-295. https://doi.org/10.1215/15314200-4-2-289 
Saarinen, K., \& Vakkari, P. (2013). A sign of a good book: Readers' methods of accessing fiction in the public library. Journal of Documentation, 69(5), 736-754. https://doi.org/10.1108/JD-04-2012-0041

Saldaña, J. (2016). The coding manual for qualitative researchers (3rd edition.). SAGE Publications, Inc.

Serafino, P. (2019). Exploring the UK's digital divide. Office for National Statistics. https://www.ons.gov.uk/peoplepopulationandcommunity/householdcharacteristics/ homeinternetandsocialmediausage/articles/exploringtheuksdigitaldivide/2019-03-04

Shenton, A. K. (2004). Strategies for ensuring trustworthiness in qualitative research projects. Education for Information, 22(2), 63-75. https://doi.org/10.3233/EFI-200422201

Siegel, H. (1997). Rationality redeemed? Further dialogues on an educational ideal. Routledge.

Stansfield, J., \& Bunce, L. (2014). The relationship between empathy and reading fiction: Separate roles for cognitive and affective components. Journal of European Psychology Students, 5, 9-18.

Sutrop, M. (2002). Imagination and the act of fiction-making. Australasian Journal of Philosophy, 80(3), 332-344. https://doi.org/10.1093/ajp/80.3.332

Tamir, D. I., Bricker, A. B., Dodell-Feder, D., \& Mitchell, J. P. (2016). Reading fiction and reading minds: The role of simulation in the default network. Social Cognitive and Affective Neuroscience, 11(2), 215-224. https://doi.org/10.1093/scan/nsv114

Thayer-Bacon, B. J. (2000). Transforming critical thinking: Thinking constructively. Teachers College Press. 
Veros, V. (2020). The selective tradition, the role of romance fiction donations, and public library practices in New South Wales, Australia. Information Research, 25(2). http://informationr.net/ir/25-2/paper860.html

Via Rivera, M. (2019, September 3). Is reading for fun teaching information literacy? Reflections on the Cambridge EcoFiction Bookgroup. Cambridge Information Literacy Network. https://camiln.org/2019/09/03/is-reading-for-fun-teaching-informationliteracy-reflections-on-the-cambridge-ecofiction-bookgroup/

Ward, D. (2006). Revisioning information literacy for lifelong meaning. The Journal of Academic Librarianship, 32(4), 396-402. https://doi.org/10.1016/j.acalib.2006.03.006

Ward, M., \& Saarti, J. (2018). Reviewing, rebutting, and reimagining fiction classification. Cataloging \& Classification Quarterly, 56(4), 317-329. https://doi.org/10.1080/01639374.2017.1411414

Westbrook, L. (1994). Qualitative research methods: A review of major stages, data analysis techniques, and quality controls. Library \& Information Science Research, 16(3), 241-254. https://doi.org/10.1016/0740-8188(94)90026-4.

Williams, M., \& Moser, T. (2019). The art of coding and thematic exploration in qualitative research. International Management Review, 15(1), 45-55.

Zunshine, L. (2006). Why we read fiction: Theory of mind and the novel. Ohio State University Press. 


\section{Appendix A}

\section{Topic sheet for interview session 1}

1. Could you name a few of your favourite authors/writers?

2. Are you mainly a fiction or nonfiction reader?

a. How would you describe your habits or preferences in terms of reading fiction versus nonfiction?

3. Transportation

a. When you read, do you tend to be very transported (so you lose track of your surroundings)? Please describe...

b. Do you put yourself inside of the text, or do you feel quite separate?

i. Do you step into the author's position, or put yourself in the shoes of the figures in the text?

4. What is critical thinking?

a. What kinds of adjectives would best describe a critical thinker?

b. Do you think there is single 'true' or correct answer to most issues?

i. Do you think there are issues on which we can all be equally right even if we disagree?

c. Do you think your critical thinking approaches have changed over time across your lifespan?

5. Critical Thinking when reading 
a. Can you describe any kinds of evaluations that usually go through your mind while reading?

i. For example, do you guess what will come next in text? Do you judge the author's intentions?

b. How would you characterise the similarities or difference in the way you think during reading fiction versus nonfiction?

i. Can you describe the evaluations you typically make when reading nonfiction?

1. What about fiction?

6. What might reading contribute to how you think critically in everyday life?

a. In what ways might fiction reading improve critical thinking in everyday life?

b. In what ways might nonfiction reading improve critical thinking in everyday life?

\section{Topic sheet for interview session 2}

1. Can you briefly describe the text you chose to read?

2. How immersive was your reading experience?
a. Did you identify strongly with the author or any figures in the text?
b. How clearly did you picture the scenes being described? 
c. Did you read the text in long reading stretches? Or did you split into small bites?

i. What do you think you gain from small bites of reading? And what about long sessions?

3. Critical thinking about your text

a. Can you describe an example of something in the text that made you think critically?

i. Did you stop reading to think critically, or did you do the thinking afterwards?

ii. Did you come to any conclusions?

b. Did the book contain different beliefs and perspectives from your own?

i. How did it feel to read those?

4. Change to your thinking

a. Can you give any examples of how this text has changed the way you think about anything?

b. Is there anything from the text that you will continue to think critically about?

5. Reading choice

a. How do you think your choice of books influences your thinking habits?

b. What do you want from the next book you are going to read? 
c. I am looking to improve my critical thinking - can you recommend me a book to read that you think would boost my critical thinking?

i. Why this book? 